\title{
UNIVERSITY STUDENTS' GROUP CULTURE FORMATION WITHIN ROLE PROFILES
}

\author{
[Formování skupinové kultury vysokoškoláků v rolových modelech] \\ Dagmar Svobodová ${ }^{1}$ \\ ${ }^{1}$ Slezská univerzita, Obchodně podnikatelská fakulta, Univerzitní nám. 1934/3,733 40 Karviná \\ Email:svobodova@opf.slu.cz.
}

\begin{abstract}
The aim of this work is to provide a conceptualization and comparison of Belbin's group roles for selected university students with the archetypes for their group culture. Its first chapter describes Belbin's concept of the workgroup and the typology for Belbin's group roles. The second chapter introduces the methodology of a case study performed using structured focus groups at Silesian University's School of Business Administration in the 2017/2018 academic year and its empirical data specification methods. The third chapter compares and interprets the outputs of this case study that examines role profiles in the group culture models of selected university students based on their type of study program. The conclusion analyzes and confirms the usefulness of university students' acts of self-reflection and critical thinking for the formation of specific archetypes within what previous studies have termed group culture.
\end{abstract}

Keywords: culture, group, role profile, students, university.

JEL classification: Z13

Received: 27.8.2018; Reviewed: 17.9.2018; 22.10.2018; Accepted: 6.3.2019

\section{Introduction}

This work's objective is to conceptualize and juxtapose the role profiles of Belbin's combined group roles for selected university students with the archetypes in their group culture. We examine the impact of Belbin's group roles' purpose and functions on the group culture of selected college students from two standpoints. Firstly, whether the role profiles combined from Belbin's group roles form specific archetypes of group culture for the selected students, and if so, how. Secondly, which of the role profiles combined from Belbin's group role most strongly reinforce the formation of specific archetypes of group culture for the selected students, and which, on the contrary, most strongly hinder their formation. The theoretical foundations for this work lie in the workplace group concept as interpreted by Kuchyňka (1992) and Mohauptová (2013). Based on the strengths and weaknesses of Belbin's group roles, we place them into the role profiles of Plaminek's model (2009) as a basis for the conceptualization of the specific group culture archetypes of the selected university students. The basic research type used was a case study, performed using structured focus groups. Based on the specific archetypes of group culture in Plamínek's model (2009), one could expect a different influence and impact of self-reflection on critical thinking for selected university students in structured focus groups about the functions and purpose of Belbin's group roles. The selected university students were able to approach the formation of group culture in a more realistic fashion by reflecting on and thinking critically about the purpose and functions of these archetypes and to follow research questions:

1) To which type within Plaminek's model do the selected university students incline the most over the course of the formation of a group culture? 
2) How can one influence within the self-reflection of selected university students about of functions and purpose of Belbin's group roles within Plaminek's model, with the aim of forming a group culture?

3) How do the selected students reflect and critically think about the functions and purpose of Belbin's group roles combined into Plaminek's model's role profiles?

4) How did the selected university students self-reflect as to which of the Plaminek model's role profiles impacts group culture formation the most and conversely, which one hinders it?

5) What are the differences between the selected students' specific archetypes for group culture depending on their type of study program?

\section{The Workgroup Concept}

Kuchyňka (1992) classifies perpetual, permanent, and unchanging existence with an assigned workload among the attributes of a workgroup. Superiors and subordinates are divided by formal distance and superiority, homogeneous composition, and a predominantly monoprofessional orientation. The positions and roles (the functions) of its members are each determined, according to O'Sullivan (2000), by an organizational scheme and labeled by an official title. This is accompanied by further administrative work, bureaucracy, routine, traditional procedures, paperwork, and accounting. According to Trice and Beyer (1993), the members of a workgroup are not obliged to concern themselves with issues outside of their specific interests within their assigned workload. They are hesitant to proceed differently, due to their adherence to strict professional procedures with no respect to the urgency of a particular situation.

Once a workgroup has been active for a long period of time, its group dynamics become according to Miller (2010) less transparent. As changes arrive, it fluctuates more quickly from one stage to another. If a new individual joins in, the workload and work system change, and the hierarchical order for the workgroup and the group team dynamics undergo a restart. Group processes are not too distinct; this is why, according to Sharry (2003), workgroups focus on mutual interactions and return to their original work style. However, should a new superior with a different work style and leadership style arrive, then, according to Baguley (2003), the workgroup sees a makeover of its personnel composition, and a fairly large overall change as well. According to Schein (2010), workgroups propose their own values and basic working style over the course of their development. Their values determine their group culture, and hence every workgroup designs its own norms and rules, targeted either at enforcing individuality " $I$ " or at enforcing the integrity of the work group "WE." According to Argyle (2013), the social context of everyday life influences members' ability to orient themselves among principles and determines their group behavior, and likewise their group culture. In regard to orientation among principles and members' group behavior, Mohauptová (2013) classifies workgroups into three types: nice, aggressive, and healthy.

Nice workgroups are, according to Mohauptová (2013), demarcated by their integrity and the mutual understanding and acceptance of their members, who trust other members and presume they are doing their best. They are distinct in their high tolerance for the mistakes and shortcomings of others. It is a challenge to find individual responsibility here, due to the prevalence of high conformity among the members of a nice workgroup team. Members express their discontent with consideration and without personal attacks. A nice workgroup devotes little focus towards performance, which is scarcely measured. Members are goodwilled towards one another, are conservative, and follow approved work procedures. Remuneration is divided into a group part and fixed salaries; wages are used as an invariable 
component of these salaries. The sharing of information and experience is encouraged within nice workgroups. The members of a nice workgroup are perceptive of mutual dependency. Unacceptable members are banished by the nice workgroup and then leave. In a nice workgroup, the "WE" spirit is what prevails long-term.

Aggressive workgroups, according to Mohauptová (2013), have strong personalities at their disposal who are ravenous individuals not reluctant to turn on each other. These groups are oriented predominantly toward performance, contention, mutual competition, and mutual comparisons. Communication is highly dynamic, with conflicts being a part of one's argumentation. Little tolerance is given to shortcomings and mistakes, which are not forgiven, and hence mutual respect is weakened. In an aggressive workgroup, coalitions and oppositions emerge in terms of US versus THEM with extreme frankness, in the sense of "we tell each other everything, whether it's nice or not." Ambition serves as the propellant. Should the attainment of a common goal be at stake, members tend to behave inimically towards one another. Remuneration is typically distributed according to individual performance; however, it may also be distributed according to the ranking for the members of the aggressive workgroup in respect to their performance. The members of an aggressive workgroup are independent of each other in their work. The weakest individuals are openly cast out and leave. In an aggressive workgroup, the "I" spirit is what prevails long-term.

Healthy workgroups are according to Mohauptová (2013), demarcated by courage due to their drive. Each member is unique, and the cooperation among them is profitable. Honesty in the healthy workgroup is concentrated into mutual respect among the members. Having different opinions is allowed, and these opinions are expected to be expressed and clarified. Nice and healthy humor is valued. Every member bears responsibility for themselves and joins in on the healthy workgroup voluntarily, based on their own free will. Feedback from its members functions excellently. Each member identifies with the group team's objectives and strives to achieve them. They are aware of the impact of their work on the group success. Remuneration is composed of three equally balanced parts: a group part, an individual part, and bonuses. The working dependency among members, as well as the autonomy of individuals within their tasks, is well perceived. Members are capable of joining forces to overcome challenges of every type. When something goes awry, they are capable of discussing it with respect. They work on their personal and professional development continuously. In a healthy workgroup, the spirit of "STRIVING FOR GOALS" is what prevails.

\subsection{Belbin's Group Roles and Plamínek's model}

Belbin's typology of group roles in the group culture can be applied to the formation of healthy workgroups and the choice of their members. All of Belbin's group roles are equally important for the optimal functioning of a healthy workgroup. In Belbin's typology (1981), he describes nine group roles, which differ from each other via the sets of shortcomings and strengths that they have available:

1) The Plant is creative, full of ideas, and unconventional. They are concerned with their own ideas to such an extent that they are sometimes no longer capable of effective cooperation. However, they are distinct in their strong penchant to take credit when the work of the group has accrued better results.

2) The Resource Investigator is an enthusiastic and communicative extrovert who searches for resources and favorable opportunities and develops contacts. However, they are also an optimists who lose interest once the initial euphoria wears off. 
3) The Coordinator clarifies targets and supports roles that have decision-making and distribution responsibilities. They meanwhile tend, however, to manipulate the other members of the workgroup and delegate their own tasks to others and subsequently take credit for the whole group.

4) The Shaper is inspirational, demanding, and dynamic. Due to their wealth of energy and courage to overcome obstacles, they are comfortable with cooperation under pressure. However, they like to tease and hurt the feelings of other members due to their incapability to make light of problematic situations or to apologize in a conflict.

5) The Monitor Evaluator views the subject of interest for the group sensibly and ponders it deeply. They are able to evaluate possible alternatives and possess the right judgment. However, they lack ambition and the ability to incentivize others. They tend to be quite critical and irrationally cynical.

6) The Teamworker is cooperative, modest, perceptive, and diplomatic. They are able to listen actively, be constructive, and settle conflicts. In key situations, however, they are indecisive and are easily influenced, and in addition, they avoid stressful situations.

7) The Implementer is disciplined, dependable, conservative, and productive. They turn thoughts and ideas into actions. On the other hand, due to their inflexibility and reluctance toward changes, they are slow to react to new opportunities.

8) The Completer Finisher is meticulous, eager, and earnest. They submit the results of their work on time. They also ferret out others' errors and failures. Yet due to their scrupulousness, they have a penchant for irrational anxiety. Also, they are not eager to delegate responsibility to others and are obsessed with detail.

9) The Specialist is focused, proactive, and devoted. They have exceptional knowledge and skills. However, they contribute to the group to a limited degree. They sometimes cannot comprehend the overall subject for the group work and for its cooperation. They ignore factors that do not lie within their field of activity.

It can be useful to observe the impact of Belbin's group roles on the formation of healthy workgroups and their group culture for the case of modern university students' organizational behavior. According to Cherrington and collective (1994), organizational behavior can be defined as uniting into workgroups during communal activities, and according to Martin (2002), it also encompasses the mapping of how life territory is organized, which is something with which modern university students are hesitant to cope. Their group culture is formed by according to Preda (2005) cultural figures such as global social network participants, which do serve for the sharing of opinions and emotions, but do not connect with the social context of everyday life. From this the necessity stems to motivate them to selfreflect about the Belbin's group roles, which Plamínek (2009) distributes into three role profiles:

1) The Thinkers focused on thinking. We place the group roles of Monitor Evaluator, Plant, and Specialist the procurers of ideas into this profile.

2) The Movers focused on processes. We place the Completer Finishers, Shapers, and Implementers among who urge others to complete tasks into this profile.

3) The Caretakers focused on people. We place the Coordinators, Teamworkers and Resource Investigators among who take care of members' well-being into this profile.

\section{The Methodology of the Case Study and the Specification of Empirical Data}

By reflecting on and thinking critically about the purpose and functions of these archetypes to follow these research questions. The objective of the researcher's strategy was to time each 
question Belbin group role orientation test in such a way that the full-time and combinedstudy respondents in the structured focus groups could understand the impact functions and purpose of Belbin's group roles. Due to the intended objective, basic design research was processed info the form of as a case study, with the application of research method related to structured focus groups. To which type within Plaminek's model do the selected university students incline the most over the course of the formation of a group culture? Due to the low initiative of university students within the context of everyday life to unite into workgroups during communal activities, we can presume that they lean towards the Movers role profile, focused on processes, within Plamínek's model. Yet without the development of appropriate self-reflection, we can expect that we will continue to produce university students with a low level of critical thinking, unable to form a group culture within the social context of everyday life. The virtual reality of social networks, which serve as clubhouses for modern university students, offers a safe space for their effortless individualization without the impact of selfreflection on critical thinking about the functions and purpose of Belbin's group roles. Modern university students are prone to believe that a group culture can only be molded on the level of social networks' virtual reality.

How can one influence within the self-reflection of selected university students about of functions and purpose of Belbin's group roles within Plaminek's model, with the aim of forming a group culture? The study's respondents, who participated within the social context of everyday life in self-reflection with an impact on their critical thinking about the functions and purpose of Belbin's group roles for the formation of a group culture, were not an ordinary university student population. The subjects that they had signed up for at Silesian University's School of Business Administration (SU SoBA) were Sociology and Organizational Sociology, and they had thus already expressed an active interest in the stated research topic. The research took place within the framework of interactive education for both subjects, in the form of collecting empirical data by having respondents fill out a Belbin group role orientation test.

\subsection{Structured focus groups as the research method for the case study}

Morgan (1997) describes structured focus groups as a research method for obtaining qualitative empirical data, with the use of group interaction in a discussion respective to a topic submitted by the researcher. The researcher determines both the direction of the group's discussion and the focal point, which is derived from the research objective and from research inquiries made to respondents. The focal point can be defined more loosely as a topic domain or a phenomenon that is the subject of examination. It must be delimited and transparent for all the participants in the group discussion. In our case, the focal point for the research was examining the functions and the impact of the purpose of Belbin's group roles within Plaminek's model for the formation of a group culture for selected university students. The message from respondents' behavior and actions is connected to the environment in which the structured focus group is situated and is composed of interactions within the discussion. Structured focus groups are assembled and managed by the researcher, who first delimits the focal point and then directly moderates the content and course of the process for acquiring qualitative empirical data. In addition to basic communication strategies and skills, it is important for the researcher to have the ability to work with a group dynamics. According to Calderon, Baker, and Wolf (2000), in connection with group dynamics, structured focus groups provide contributions to the collective meaning of the language, values, wishes, and opinions of a target group. It is advisable that they know how to influence the delimited focal point with group phenomena. In our case, the impacts of the self-reflection of selected university students on their critical thinking the about functions and purpose of Belbin's 
group roles within Plaminek's model for the formation of group culture as the group phenomenon.

We communicated with structured focus groups, wherein all respondents were asked questions simultaneously. The respondents knew the topics of Belbin's group roles orientation test and the order of the questions asked. The researcher here operated as the group discussion moderator under the question methodology expounded by Gray, Brown, and Macanufo (2010) in question-answer mode. Structured focus groups took place in the same environment with a fixed, 45-minute time frame. The respondents in the structured focus groups were aware of what was expected of them, and the same space for self-expression was allotted to all. The researcher had access to a list of participating respondents for use in addressing the respondents, and a topic list in a form that helped them find their bearings quickly. Every respondent had a note sheet for notes prepared beforehand, which they used whenever a topic came up that matched the notes. The advantage here was the high level of uniformity in the notes, due to the use of identical source materials. The time and topic restrictions for structured focus groups helped to provide consistent empirical data for the fundamental topics. The structured focus groups took place in four stages.

The first stage was the initiation, when it was crucial to designate the places of the researcher and the respondents. Basic rules were laid before involving any respondents in the group discussion. These rules were: only one person may speak at a time, no secondary conversations may take place among respondents, all respondents have to join in on the group discussion, no respondent holds a dominant role, and everyone may present their own opinion and react to others' opinions and may refuse to answer a question that makes them uncomfortable or refrain from discussion, should they not want to answer anymore, and end participation in the group by their own will. The information obtained must not be handed to people not involved in the group, all respondents are to be addressed by their first names, the reports must serve for research purposes only, and personal data must be protected.

The second stage was the initial discussion and motivational work with respondents. A group discussion took place about the impacts of the selected university students' self-reflection and critical thinking about the functions and purpose of role profiles of Thinkers, Movers, and Caretakers on the formation of a group culture. Within this process, we used in line with Zahrádková (2005) a teambuilding strategy as a path to cooperation, and with the help of a funneling process, we worked towards narrowing the research topic. We explained to respondents how the impact of self-reflection on their critical thinking about the functions and purpose of Thinkers, Movers, and Caretakers serves within Plaminek's models to form a group culture within the social context of everyday life.

The third stage was advancing towards the core of the structured focus group, which was the central point of the case study. The objective of the researcher's communication strategy was to time each question in such a way that the full-time and combined-study respondents in the structured focus groups could understand the impact of their critical thinking about the functions and purpose of the role profiles of Thinkers, Movers, and Caretakers on the formation of group culture. Some of the respondents were able to join in on the group discussion more quickly than others. The researcher directed their group dynamics during the discussion so that no one respondent would dominate. The researcher maintained each group discussion until the time limit ran out or until all respondents had provided relevant consistent empirical material to assess the focal topic. 
In the fourth stage, the researcher concluded the structured focus group by letting the discussions on its focal topics reach their end and checking at what point in the discussion the respondents were situated. Respondents were given space to express themselves further on the topic in accordance with their needs, enabling the researcher and other participants to gain feedback. The respondents thus become aware of what the impact of their critical thinking about the functions and purpose of the role profiles of Thinkers, Movers, and Caretakers in Plaminek's model for group culture forming was. The numbers of respondents for the structured focus groups was based on the case study's technical and scheduling possibilities. Each structured focus groups each contained 10 members. For this reason, the position and role of Observer was introduced. The number of structured focus groups chosen was influenced by the need for complete case-study results. With this group count, the case could conceptualize, demonstrate, and interpret the results of the three role profiles in Plamínek's model in combination with Belbin's group roles in healthy workgroups. In parallel, it advised the selected university students regarding how to serve as specific archetypes within a group culture. The basic set is of SU SoBA university students of bachelor's study program for 2017/2018. According to Disman (2002), we define a minority of the basic set as a selective sets. The selective sets are a groups of units that we examine actually. According to Žižlavský (2003), the representativeness of the selective sets are influenced by the methodology of selecting units. Each unit of the basic set has the same chance of getting into the selective sets. There are a gnoseological relationships between the basic set and the selective sets. (Table 1)

Table 1: The basic set of SU SoBA university students for 2017/2018

\begin{tabular}{|c|c|c|c|}
\hline \multicolumn{4}{|c|}{ Type of university study program } \\
\hline All & 1286 & & $100.00 \%$ \\
\hline \multirow[b]{2}{*}{ Bachelor's study program } & Full-time & 759 & $59.02 \%$ \\
\hline & Combined & 527 & $40.98 \%$ \\
\hline
\end{tabular}

Source: Silesian University, School of Business Administration 2018 [online] [viewed 7.9.2018] Accessible at: <http://www://stag.slu.cz/portal/studium/prohlizeni.html/>.

From a gnoseological point of view, the relationship is representative between the basic set and the selective sets. Two selective sets were construed for the case study via deliberate selection. Based on the designated groups for the basic set, we selected the number of respondents for each selective set separately from the groups of students based on their registration for the Sociology and Organizational Sociology study subjects. According to Miovsky (2009), the prerequisite for applying deliberate selection is the description of the differentiating criterion on the basis of which basic set groups are differentiated. In our case, the differentiating criterion was the type of university studies. Once the requirements of the differentiating criterion were met, the structured focus groups were designated to select respondents from among registered university students. The objective was to create selective sets of students in the 2017/2018 academic year at SU SoBA such that they would be able to provide qualitative empirical data for the conceptualization of the role profiles in Plamínek's model and specific types of group culture. The selective sets consisted of bachelor's-program students who had signed up for the Sociology of Organization subject for the 2017/2018 winter semester. These are closed groups given by the year of study and the students did not know each other. $128(100.00 \%)$ of the respondents were assigned to the selective sets based on their type of study program. Out of the full count, $71(55.47 \%)$ were full-time students and $57(44.53 \%)$ were combined-study students. (Table 2 ) 
Table 2: Selective sets of students at SU SoBA in 2017/2018

\begin{tabular}{|c|c|c|c|}
\hline \multicolumn{4}{|c|}{ Type of university study program } \\
\hline All & 128 & & $100.00 \%$ \\
\hline \multirow[b]{2}{*}{ Bachelor's pro } & Full-time & 71 & $55.47 \%$ \\
\hline & Combined & 57 & $44.53 \%$ \\
\hline
\end{tabular}

Source: own

\section{The Case Study's Results}

The analysis of empirical data in a case study is done through an integrated research approach. According to Loučková (2010), the outputs of the integrated research approach can analyzed using a combination of qualitative and quantitative approach. The choice of combination with a predominantly qualitative or quantitative method is done by to the researcher's decision based on the research intent. In our case, the empirical data of the case study are generated by description, interpretation and generalization in the structured focus groups (qualitative approach) based on Belbin group role orientation test (quantitative approach). Respondents' research operations describe qualitatively empirical data that the researcher processes by a quantitative method (arithmetic mean).

The conceptualization of the Thinker, Mover, and Caretaker role profiles in Plamínek's model originates from Belbin's group roles. How do the selected students reflect and critically think about the functions and purpose of Belbin's group roles combined into Plaminek's model's role profiles? The selected students reflected on the functions and purpose of Belbin's group roles combined into Plamínek's model's role profile by means of an orientation test, which was divided into seven sections. Each of seven sections contained nine statements. The sections were: I. I can be useful to a workgroup when... II. If I had a shortcomings in group work, it would be... III. When I cooperate on a project with others, I'm... IV. My typical approach towards group work is distinct in that... V. I like group work, because... VI. When I am assigned to a difficult task that I must complete in a limited time with unknown collaborators, I'm... and VII. I approach the problems to which I am assigned in group work in a way that.... In each section, respondents circled the statements that describe them best. They could circle one, two, or more of the nine statements, towards which they distributed a maximum of ten points. E.g., in one section they circled three statements that they deem represent them best. One statement represents the surveyed students as a respondent fully accurately, while the other two only partly. In this case, they could distribute six or seven points to the first statement, and the rest between the two remaining ones. In another section, they could decide to mark two statements which represent them equally accurately. Should this be the case, they distribute five points to both. In the next section, they might circle seven statements. One statement represents them more accurately, so they assign three points to it. The second is more accurate than others, so they would assign two points to it, while assigning one point each to the rest of the statements. According to Bělohlávek (2008), the orientation test has an ipsative character, because respondents distribute all ten points among Belbin's group roles.

How did the selected university students self-reflect as to which of the Plaminek model's role profiles impacts group culture formation the most and conversely, which one hinders it? Each respondent received results via the evaluation of their orientation test. This evaluation is determined by their personal ordering of Belbin's combined group roles from the important to the least important. The order of combined Belbin's group roles served all respondents as the foundation for their personal conceptualization of the three role profiles under Plamínek's model: 
1) The influence of selected university students' self-reflection on their critical thinking about the functions and purpose of Thinkers (Monitor Evaluators, Plants, and Specialists), focused on thinking and providing ideas.

2) The influence of selected university students' self-reflection on their critical thinking about the functions and purpose of Movers (Completer Finishers, Shapers, and Implementers), focused on processes and urging others to fulfill tasks.

3) The influence of selected university students' self-reflection on their critical thinking about the functions and purpose of Caretakers (Coordinators, Team workers, and Resource Investigators), focused on people and taking care of others' well-being.

Every role profile reflects the impacts of the selected university students' self-reflection on their critical thinking about the functions and purpose of Thinkers, Movers, and Caretakers and their contribution to the formation of a group culture. It is calculated by applying the arithmetical average $(\mathrm{X})$ of the personal rankings of the respondents' combined Belbin group roles as the sum of all values divided by their number. (Table 3)

$$
x=\left(x_{1}+x_{2}+x_{3}+\ldots+x_{n}\right) / n
$$

Table 3: The role profiles of SU SoBA students in the 2017/2018 academic period

\begin{tabular}{|l|l|l|l|l|l|l|l|}
\hline Rank & $\begin{array}{l}\text { Belbin role } \\
\text { of full-time students }\end{array}$ & $\mathrm{x}$ & $\begin{array}{l}\text { Role profile of } \\
\text { full-time } \\
\text { students }\end{array}$ & Rank & $\begin{array}{l}\text { Belbin role } \\
\text { of combined students }\end{array}$ & $\begin{array}{l}\text { Role profile of } \\
\text { combined } \\
\text { students }\end{array}$ \\
\hline 1. & Team worker & 3.49 & Caretakers & 1. & Implementer & 3.46 & Movers \\
\hline 2. & Shaper & 3.76 & Movers & 2. & Completer Finisher & 3.84 & Movers \\
\hline 3. & Plant & 4.63 & Thinkers & 3. & Resource Investigator & 4.09 & Caretakers \\
\hline 4. & Implementer & 4.96 & Movers & 4. & Shaper & 4.74 & Movers \\
\hline 5. & Coordinator & 5.11 & Caretakers & 5. & Specialist & 4.81 & Thinkers \\
\hline 6. & Resource Investigator & 5.44 & Caretakers & 6. & Plant & 5.02 & Thinkers \\
\hline 7. & Completer Finisher & 5.68 & Movers & 7. & Monitor Evaluator & 6.12 & Thinkers \\
\hline 8. & Specialist & 5.89 & Thinkers & 8. & Team worker & 6.25 & Caretakers \\
\hline 9. & Monitor Evaluator & 6.01 & Thinkers & 9. & Coordinator & 6.71 & Caretakers \\
\hline
\end{tabular}

Source: own

The role profiles within Plamínek's model amount to archetypes for a group culture among the selected university students, which we can compare in the social context of everyday life. These are specific archetypes for thinking, moving, and caretaking group cultures, which are important and useful for the selected university students in the social context of everyday life. What are the differences between the selected students' specific archetypes for group culture depending on their type of study program? Below the different orderings of the specific archetypes for group culture for the selected SU SoBA students depending on their type of study are shown in respect to the role profiles in Plamínek's model. (Table 4)

Table 4: Group (team) culture of SU SoBA students in the 2017/2018 academic period

\begin{tabular}{|c|c|c|c|c|c|}
\hline Rank & $\begin{array}{l}\text { Culture archetype } \\
\text { for full-time } \\
\text { students }\end{array}$ & $\begin{array}{l}\text { Role profile } \\
\text { of full-time students }\end{array}$ & Rank & $\begin{array}{l}\text { Culture archetype } \\
\text { for combined } \\
\text { students }\end{array}$ & $\begin{array}{l}\text { Role profile } \\
\text { of combined students }\end{array}$ \\
\hline \multirow[b]{3}{*}{1.} & \multirow[b]{3}{*}{ Mover } & Shaper & \multirow[b]{3}{*}{1.} & \multirow[b]{3}{*}{ Mover } & Implementer \\
\hline & & Implementer & & & Completer Finisher \\
\hline & & Completer finisher & & & Shaper \\
\hline \multirow[b]{3}{*}{2.} & \multirow[b]{3}{*}{ Caretaker } & Team worker & \multirow[b]{3}{*}{2.} & \multirow[b]{3}{*}{ Thinker } & Specialist \\
\hline & & Coordinator & & & Plant \\
\hline & & Resource Investigator & & & Monitor Evaluator \\
\hline \multirow[b]{3}{*}{3.} & \multirow[b]{3}{*}{ Thinker } & Plant & \multirow[b]{3}{*}{3.} & \multirow[b]{3}{*}{ Caretaker } & Resource Investigator \\
\hline & & Specialist & & & Team worker \\
\hline & & Monitor Evaluator & & & Coordinator \\
\hline
\end{tabular}

Source: own 


\section{Conclusion}

This comparison and conceptualization of Plamínek's model role profiles has confirmed differences among the students at SU SoBA. Differences between selective sets of students at SU SoBA are influenced by their type of study program and differing preferences. Depending on the type of study program, there is a typical specific role profile for each selective set. The case study's results confirm that combined-study program students incline most towards the Mover profile within Plamínek's model, focused on processes. The influence and effects of combined-study students' self-reflection on the development of critical thinking about the functions and purpose of Belbin's group rules, which confirm their differing preferences, are what lead them to prioritize the Mover role. For both of the selection groups, the Mover culture influences the formation of group culture the most. The differing preferences show that Thinker culture most strongly hinders the formation of group culture for full-time students, while Caretaker culture does so most strongly for the students of the combinedstudy program. However, with the process of conceptualization within the social context of everyday life, the selected students gain awareness of the importance of the effects of selfreflection on the development of critical thinking about the functions and purpose of the Thinker, Mover, and Caretaker roles for the formation of group culture. The combining of the purpose and functions of Belbin's group roles helps with both realistic reflection and critical thinking on one hand, and the practical formation of group culture on the other. For this reason, one can recommend to the selected students that they form a group culture through a personal orientation towards the purpose and functions of the combined Belbin group roles. One's personal combination of the purpose and functions of Belbin's group roles will change with age, and also with experience.

The gnoseological relationship shows that both selective sets represent the basic set. It follows that the research results of the selective sets represent the basic set of SU SoBA university students of bachelor's study program for 2017/2018. We therefore draw our conclusions only for university students assembled into selective sets. In this case, the limits of the given research results can be seen in the generalization of specific group culture archetypes based on the role profiles in Plamínek's model (2009) for selected students at SU SoBA only. On the other hand, the results of this case study under the Plamínek model are understandable. Within the social context of everyday life, how do the selected students reflect upon and critically think about the functions and purpose of the role profiles in Plaminek's model for the formation of group culture? Through the identified role profiles, the selected students become aware of the usefulness of their specific chosen archetype for the formation of group culture for themselves. Why did we only work with students at the SU SoBA bachelor's program only, when the virtual generation of modern university students is larger than this? This was because the Sociology and Social Organization subjects are active for the given target group at SU SoBA, and the case study was performed within these. The objective of the researcher's communication strategy was to time each question in such a way that the students in the selective sets would reflect upon the purpose and functions of Belbin's group roles within the role profiles of Plamínek's model. The selected students' self-reflection, along with the impact on their critical thinking about the functions and purpose of the role profiles, could then help them realistically approach the formation of the specific archetype for group culture.

In what ways is the self-reflection of the selected students along with its impacts on the development of their critical thinking about the purpose and functions of the profiles within Plaminek's model unique? The selected students are future Movers (in the case of the combined-study students Implementers, Completer Finishers, and in case of full-time students 
Shapers) oriented towards processes, urging the completion of tasks as challenges within digital systems. They are a virtually oriented generation, and they reflect upon role profiles as cultural figures on social networks. By training their IT literacy on computers, where they dynamically change their direction and pace, they develop critical thinking about the functions and purpose of their role profiles. They are interested in teaming up on social networks. Within the social context of everyday life, an individual approach suits them, due to their desire to be independent. They are intellectually curious, but they lack confidence. For these reasons, this generation does not like to socialize in traditional clubhouses, but instead wants the Movers' type of group culture, with the virtual purpose and functions of Implementers, Shapers and Completer Finishers.

\section{Acknowledgement}

This article was created under support of the Ministry of Education, Youth and Sports under the Institutional Support for long-term strategic development of the Silesian University in Opava, Faculty of Business Administration in Karviná in year 2018.

\section{References}

[1] ARGYLE, M., 2013. The Social Psychology of Everyday Life. London: Routledge. ISBN 9781134961733.

[2] BELBIN, R. M., 1981. Management teams - why they succeed or fail. Oxford: Butterworht Heinemann. ISBN 0-7506-0253-8.

[3] BĚLOHLÁVEK, F., 2008. Jak vést svioj tým. Praha: Gradu Publishing. ISBN 978-80247-1975-7.

[4] BAGULEY, P., 2003. Teach Yourself Teams and Team-Working. London: Hodder Headline Ltd. ISBN 978-03-407-9044-1.

[5] CALDERON, J. L., R. S. BAKER and K. E. WOLF, 2000. Focus groups: A qualitative method complementing quantitative research for studying culturally diverse groups. Education for health, 13(1), 91-95. ISSN 1357-6283.

[6] DISMAN, M., 2002. Jak se vyrábí sociologická znalost. 3. vyd. Praha. Karolinum. ISBN 80-246-0139-7.

[7] GRAY, D., S. BROWN and J. MACANUFO, 2010. Gamestorming. San Francisco: O’Reilly. ISBN 978-0-596-80417-6.

[8] CHERRINGTON, D. J., eds., 1994. Organizational Behavior. The management of individual and organizational performance. Boston: Allyn and Bacen. ISBN 0-20511959-X.

[9] KUCHYŇKA, Z., 1992. Organizování a ř́zení týmové činnosti. Praha: Institut moderního průmyslu. ISBN 80-85021-03-X.

[10] LOUČKOVÁ, I., 2010. Integrovaný přistup v sociálně vědním výzkumu. Praha: SLON. ISBN 978-80-86429-79-3.

[11] MARTIN, J., 2002. Organizational Culture. Mapping the Terrain. London: Sage Publications. ISBN 0-8039-7294-6.

[12] MILLER, B. C., 2010. Nice Teams Finish Last: The Secret to Unleashing Your Team's Maximum Potential. New York: AMACOM. ISBN 9780814413944.

[13] MIOVSKÝ, M., 2009. Kvalitativní přistup a metody v psychologickém výzkumu. Praha: Grada Publishing. ISBN 80-247-1362-4. 
[14] MOHAUPTOVÁ, E., 2013. Týmový koučink. Praha: Portál. ISBN 978-80-262-0350-6.

[15] MORGAN, D. L., 1997. Focus groups as qualitative research. 2nd ed. London, New Delhi: SAGE Publications. ISBN 0-7619-0343-7.

[16] O'SULLIVAN, M., 2000. Contests for Corporate Control. Corporate Governance and Economics. Performance in the United States and Germany. Oxford: Oxford University Press. ISBN 0198293461.

[17] PLAMÍNEK, J., 2009. Týmová spolupráce a hodnocení lidí. Praha: Grada Publishing. ISBN 978-80-247-2796-7.

[18] PREDA, A., 2005. The Investor as a Curtural Figure of Global Capitalism. In: K. KNORR CETINA and A. PREDA, eds. The Sociology of Financial Markets. Oxford: University Press. p. 141-162. ISBN 0-19-929692-8.

[19] SHARRY, J., 2003. Solution-Focused Groupwork. 2nd ed. London: Sage Publications. ISBN 978-1-4129-2985-1.

[20] SCHEIN, E. H., 2010. Organizational Culture and Leadership. San Francisco: John Wiley \& Sons. ISBN 978-0-470-19060-9.

[21] TRICE, H. M. and J. M. BEYER, 1993. The Cultures of Work Organizations. Engelwood Cliffs: Prentice Hall. ISBN 978-0-13191-438-4.

[22] ZAHRÁDKOVÁ, E., 2005. Teambuilding - cesta k efektivní spolupráci. Praha: Portál. ISBN 80-7367-042-9.

[23] ŽIŽLAVSKÝ, M., 2003. Metodologie pro Sociální politiku a sociální práci. Brno: MU FSS. ISBN 80-210-3110-7. 